\title{
The broken branch: Darwin's evolutionary tree and the progress of Medicine, the evolution of specialism and generalism
}

\author{
RICHARD V. LEE, MD, MACP, FRGS
}

Professor of Medicine and Pediatrics and Obstetrics. Adjunct Professor of Anthropology and Social and Preventive Medicine. Director, Division of Maternal \& Adolescent Medicine. Director, Division of Geographic Medicine. Department of Medicine, State University of New York at Buffalo, N.Y., U.S.A.

Manuscript by invitation of the Editors. It is based in a lecture given by Dr. Lee during the XXXI World Congress of Internal Medicine, Santiago, November 11-15, 2012.

Address correspondence to: Richard V. Lee, M.D. 7664 East Quaker Road. Orchard Park, NY 14127.

716-667-3304 phone/fax. dmdrvl@buffalo.edu

\section{ABSTRACT}

The landscape of medical practice and health care has been transformed by specialization over the past Century. There has been an extraordinary acceleration in the proliferation of specialty practice, coincident with rapid growth in technological devices and their clinical applications during the past fifty years. Medicine and medical care are evolving rapidly, a process that has similarities to biologic evolution. Medical educators, policy makers, and practitioners might find a Darwinian overview of medicine and health care of interest.

(Rev Med Chile 2013; 141: 220-226).

Key words: Cultural evolution; Clinical Medicine; Darwin; General practice; Specialization.

\section{La rama quebrada: el árbol evolucionista de} Darwin y el progreso de la Medicina, la evolución de la especialización y los generalistas

El ámbito de la práctica médica y la atención de salud se ha transformado durante el siglo reciente por la especialización profesional. Ha habido un cambio extraordinariamente rápido por la proliferación de la práctica como especialistas, coincidiendo con la proliferación y el perfeccionamiento de los instrumentos y equipos tecnológicos y sus aplicaciones clínicas, durante los últimos cincuenta años. La medicina y la atención médica están evolucionando rápidamente, un proceso que tiene similitudes con la evolución biológica. Quienes son educadores médicos, los que fijan las políticas de salud y quienes practican la profesión pueden encontrar interesante una mirada Darwiniana a la medicina y la atención en salud.
It is not the strongest of the species that survives, nor the most intelligent that survives.

It is the one that is most adaptable to change.

Charles Darwin

Internal medicine in 1964, the year I graduated from medical school, was a respected career choice and internal medicine was necessary for hopeful nonsurgical subspecialists. After all, internal medicine was general medicine. Great internists were sui generis generalists. How things have changed!
For the realm of general medicine, biologic and technologic advances have created new clinical domains: for example, cardiology, gastroenterology, neurology, endocrinology, and more, each clamoring for professional, economic, and intellectual recognition. In 1964 medical school classes were composed mostly of men. Specialization was rapidly surpassing general medicine as a career choice, and the evolutionary tree of medical subspecialties was growing apace. Limitation of house staff hours and the computerization of medicine were 
in their infancy. I was optimistic in those days that the importance of generalism and the generalist physician as the progenitor species of all internists would become fundamental to the provision of care and the progress of medical science.

In the 1980s and 1990s I was writing an occasional essay for the American Journal of Medicine under the rubric "The Generalist: A Jaundiced View". It was fun to be something of a solitary curmudgeon. The medical literature had become replete with articles about generalism and generalists: surveys, studies of costs and outcomes, opinions, studies of manpower, fiction. Many of the authors, all products of what has been called a "golden age of American medicine" in the mid-20th century, were aging specialists. I now risk being just another aging commentator. By the turn of the century I became pessimistic and discouraged by the pellmell expansion of specialism and specialties and the emergence of new breeds of students, trainees, and practitioners focused exclusively upon their special niche and the lifestyle it affords.

For those of us schooled and trained in the socalled "golden years" in the United States, mentored by faculty scientists and clinicians from an old tradition, the scope, scale, and rapidity of change were disquieting and uncomfortable. My generalist essays were chastised for my skepticism about medical ethics which ignored the uncertainties of medical science and the necessity for repetitive documentation of experimental and clinical facts and outcomes. My belief that being a physician meant a lifelong calling of scholarship and care was derided as "old fashioned". My support of rigorous house staff training was labeled dangerous, inappropriate, unjust, and inhumane. So I stopped writing "generalists" for over a decade and found other topics to ruminate and write about. I became engrossed by the history of exploration, evolution, and environmental health. Now in 2012 as an "old doctor" I continue to view contemporary medicine with a jaundiced eye. I wonder and ruminate about the place of specialization, computers, gender, and "lifestyle" in the medical ecosystem with friendly -most of the time- criticism.

The past twenty-five years has been an exciting time for "splitters", but not for "lumpers". I lament about how hard it is to convince young people that general medicine is what they should consider doing. There is something not right about the plethora of papers bemoaning the sad state of general internal medicine ${ }^{1-12}$. The source of my unease is an oppressive lack of spirit, of soul, of nonnumeric adjectives. Nowhere in this vast collection of deadly serious writings do I find a description of the nature of generalism or of the personal requirements and characteristics of generalists as opposed to specialists.

What makes a generalist different from a specialist? I tend to think that specialism and generalism define states of mind, first, and occupations, second. Generalism defies easy description because generalists inhabit a cluttered, untidy world. Generalists are inclusive - welcoming. Generalists know a lot about a lot. That's something that more and more people are convinced is not possible, despite evidence to the contrary and the existence of enormous, easily available resources for storing and retrieving information. I suspect that part of the current dilemma is that it is so much easier to identify a specialist. Specialism means creating a focused, demarcated vista and playing field. Specialists have become heroes, akin to Achilles and Hector, warriors of technique in the battle for health. Specialists confine their thought and restrict their actions, avoiding clutter and vagueness. Specialists are exclusive, expert. The old saw about knowing more and more about less and less, though hyperbolic, is not entirely inaccurate.

There are six categories that demonstrate distinct differences between generalism and specialism (Table 1). The differences I have

Table 1. Categorical differences between generalism and specialism ${ }^{13}$

\begin{tabular}{|c|c|c|}
\hline & Generalism & Specialism \\
\hline Horizon & $\begin{array}{l}\text { Open } \\
\text { Broad }\end{array}$ & $\begin{array}{l}\text { Limited } \\
\text { Narrow, focused }\end{array}$ \\
\hline Concern & $\begin{array}{l}\text { Inclusive } \\
\text { Correlative }\end{array}$ & $\begin{array}{l}\text { Exclusive } \\
\text { Constrictive }\end{array}$ \\
\hline Methods & $\begin{array}{l}\text { Observation } \\
\text { Natural history }\end{array}$ & $\begin{array}{l}\text { Technical intrusion } \\
\text { Experimental artifice }\end{array}$ \\
\hline Equipment & $\begin{array}{l}\text { Portable } \\
\text { Self-contained }\end{array}$ & $\begin{array}{l}\text { Sessile } \\
\text { Equipment and } \\
\text { staff dependent }\end{array}$ \\
\hline Tempo & $\begin{array}{l}\text { "Slow" } \\
\text { Continuous } \\
\text { involvement over } \\
\text { time }\end{array}$ & $\begin{array}{l}\text { "Fast" } \\
\text { Rapid turnover of } \\
\text { multiple patients, } \\
\text { experiments, etc. }\end{array}$ \\
\hline Risk & Ignorance & Incompetence \\
\hline
\end{tabular}


chosen are descriptive, based on 50-odd years of observation, and are offered without statistical support ${ }^{13}$. A fault, to be sure, but I hope a useful fault: something to stimulate debate, even outrage, uncertainty and perhaps some fashionably correct statistical research.

Horizon refers to what the individual pays attention to, how far he or she looks, the field of vision, how the physician relates to and categorizes the external world. Horizon and concern are directly related to the content of the individual's working knowledge and active interests. The generalist tries to sense and experience as much as possible, while the specialist focuses on a small component. Generalists include as much as possible. Specialists exclude any and all that do not relate to their niche.

Generalists are observers seeking to understand rhythms and their aberrations and to comprehend the meaning of natural history. Specialists aim to control natural events; generalists want to understand them. Specialists collect and intrude upon their patients in order to establish formulas and algorithms, which become the foundations for routines. Not doing something to a patient is important for the generalist, who will stay still, watch, and wait. Doing something to the patient is essential for the specialist who tends to ignore or discard the "undoable" patient and move on to the next procedure. Generalists are schooled in patience. Specialists thrive on rapid intervention and result. The tempo of general medicine is less hurried than the tempo of specialist practice. Futility is the generalist's familiar friend and the specialist's particular frustration.

Ethical dilemmas are not abstractions for physicians who care for patients without special regard for procedures both legal and technical. Specialists need other specialists, especially ethicists to referee. Generalism is risky, but it is a different kind of risk from specialism. The risk to the generalist comes from the open door, the arrival of an unfamiliar or new circumstance. The risk to the specialist is failure to perform without flaw the special task on the selected patient. The generalist must live with the reality of ignorance and the need for constant learning; the specialist with incompetence.

Generalism is portable; specialism is sessile. The specialist depends upon equipment and support staff. As these become increasingly cumbersome and complex, the specialist becomes confined, inseparable from procedures and tools. Generalists can practice almost anywhere. Their equipment is self-contained, easily carried. Far better to have a generalist on a trek to remote regions or a town destroyed by earthquake or flood, than a specialist unable to function without the panoply of retainers and machines.

General medicine risks condescension from scientific specialty colleagues because it embraces the so-called "soft sciences": anthropology, sociology, psychology, ecology. The label of quackery can be easily applied to general medicine because the generalist refuses to condemn the utility of socalled "alternative medicine". The dilemma facing contemporary medicine is how to include the essence of generalism in academic medicine with its risk of condescension because its methods and philosophy defy reductionist, statistical science. Generalism, paradoxically, has a far greater potential for research because the generalist has such an enormous field for asking questions.

Of course my grand generalization is likely to be a target for cavil and criticism. There will be letters from highly sophisticated superspecialists telling me of their poetry writing, their chamber music playing, and their art collection. How can I demean their cultural generalism? The difference lies in compartmentalization. Specialists build fences: they create cubicles in their professional and their personal lives. The focused realm of specialism is separated intellectually, emotionally, and physically from the rest of the specialist's activity and thinking. The art collection, music, and poetry often have nothing at all to do with the special professional activity, and vice versa. The generalist has difficulty constructing boundaries. Family, medical practice, art, music, writing, and reading all tend to blur and to blend.

Years ago I was convinced that specialty training by itself was not incompatible with practicing general medicine; that training in a specialty did not inevitably or automatically extinguish the generalist state of mind. I am less sure now. The division between specialty and general medicine seems to be intensifying. At one time it made sense to insist that the generalist state of mind dominate internal medicine; that internists were generalists first and specialists second. Economics and the academy have made wealth and status imperative. The kindly old "GP" (General Practitioner) has become irrelevant and poor. I doubt that economic 
manipulation alone will resurrect or even preserve the medical generalist. Generalism requires societal embrace of an untidy, indefinite, lethargic, and risky practice of medicine. The general internist may provide a more exciting and humane kind of care, but the public has come to expect certain cure, not uncertain palliation.

The problem lies as much in the medical establishment as in the general population. Failure to promote and retain charismatic clinicians as fulltime medical school faculty is part of the problem. The transformation of general medicine into a vast business of statistical manipulation in order to label general medicine as science is another. Bedside rounds by physician teachers that focus on the individual patient, as opposed to the specialization and literature of blinded, randomized clinical trials with acceptable statistical power and of clinical outcomes research, have become a rarity.

How did this happen? Beginning with the formation of university centers of learning, establishing the academic title of professor and the awarding of degrees, medicine became a profession. Universities were the incubator of medical hypotheses and experiments which we now call biomedical science. To be entitled "doctor" meant that the candidate was required to complete a course of study, satisfy an examination by the professoriate, complete a written thesis and endure an oral examination and defense of the thesis. For almost a millennium the mantle of the physician -the hood of academic robes and the title of doctor- signified membership in one of the "learned professions". The traditional learned professions were theology, law, and medicine. Each required an intensity of scholarship, connection and communication with scholars within and beyond the university, and recognition by the wider community of scholars including the other learned professions. The degree of doctor - in law, philosophy, theology, or in medicine- meant that the candidate had completed the examination requirements and had brought new facts and interpretations to the professional and professorial community.

The medical and surgical crafts promoted the proprietary skills, clinics, potions and procedures. Barber surgeons developed tools and techniques exploring and demonstrating biologic events that became increasingly potent in the $18^{\text {th }}$ century leading up to the remarkable transformation of medical knowledge and practice beginning in the mid $19^{\text {th }}$ century to the present. Apprenticeship and practical experience continued especially for the apothecaries and barber surgeons in synchrony with the scientific formalization of the physician's role. In the $19^{\text {th }}$ century apprenticeship and independent study remained a path to medical practice. However, by the end of the century the burst of scientific advance in microbiology, surgery, anesthesiology, and immunology transformed the medical curriculum and expectations for the profession of medicine. In 1905, the editor of The Lancet, Sir Squire Spriggs, wrote that the rising scientific basis of medicine meant that physicians had to relinquish their status as one of the learned professions and accept "being classed with other practical workers who have an equal claim to be considered men of science".

To be sure science, molecular and statistical, and technology, have become the substrate of medical science and medical care today. For the past fifty years molecular and statistical knowledge and technology have evolved and exploded in content and capacity driving the need for specialized technologic practitioners and biomedical scientists. On the other hand, human beings are still pretty much the same as they have been for thousands of years. The evolution of the human species is occurring but at a glacial pace compared to the evolution of biomedical science and technology.

The pace and process of biologic evolution has much to teach us about the disparity between the realities of human life and the abstractions and artificialities of molecular medicine ${ }^{14}$. The past half century, for example, has featured the manipulation of technologies of fiber optics, canulization and imaging of vascular structures, radiographic and magnetic resonance imaging, and digital information processing, creating new technical niches and new adaptations to clinical practice. To my mind, this technologic breeding process is not dissimilar to the phenotypic manipulation of birds and animals by selective breeding that fascinated Charles Darwin in the mid $19^{\text {th }}$ century.

Trees and the creatures that populate them are a favorite part of my activities as the medical director of an environmental consulting company: perhaps because trees were the original habitat of our ancestral lineage, but more because trees are an extraordinary source for metaphor and ana$\log y^{15}$. The gross anatomy of a tree -roots, trunk, branches, leaves, blossoms, and fruits or seeds- 
contain life's cycle. The image of a tree has been used by historians, biologists, and economists to illustrate the development, growth, preservation, and reproduction of life, art, science, and society.

Darwin drew his evolutionary tree in 1837 to illustrate the possibilities of evolutionary progression $^{16,17}$. Ever since, evolution metaphors and analogies have been applied to virtually every process that living things experience and produce. Medicine is perhaps one of the most apt demonstrations of the tree metaphor and analogy. The extraordinary expansion of experimental biomedical science into the mechanisms of live creatures, their organs and constituent cells, and the technical and engineering capacity to measure and to display those mechanisms, has generated fecund growth of specialized techniques to measure and display their unique characteristics. The technical and image making capacity to expand and refine resolution and to collate measurements into multidimensional images has transformed the medical vision of patients and parts of patients. Visual inspection of the lumen of virtually every tube and cavity of the human body is possible using fiber optic devices. There are now endoscopists for each lumen: gastrointestinal, genitourinary, cardiovascular. Surgical implants and transplants, similarly, have produced orthopedic surgeons who "do" only knees, or hips, or shoulders, and transplant specialists for each viscera. From my point of view the specialist knows and works on twigs; the generalist works on the tree. The growth rate of the medical evolutionary tree, the emergence of new science and technology, has accelerated over the past century. Indeed the medical tree has become lopsided.

New clinical practice niches have become so numerous in the medical tree that the weight of the evolutionary branch, including the consumption of money and the plethora of specialized doctors, has reached a point where the evolutionary branch risks becoming unbearable, and might break ( $\mathrm{Fi}$ gure adapted from Reference 17).

During the earth's long history of life there have been bursts of extinction and speciation that follow upon changes in the earth's environment from volcanism, earthquakes, floods, and climate change. The changes in climate and environment that occur with profound and fundamental changes result in new species and tend to favour living creatures that contain and retain biologic adapta- bility. Highly specialized creatures unable to adapt to the new conditions do not survive. As the highly specialized, enormous, armored, and toothy dinosaurs succumbed to the changing earth, smaller, more resourceful mammals persevered and set in motion a new round of evolutionary extravagance. Creatures with greater adaptive resources, broader general resilience, are the stock from which new species emerge.

The genus of physicians has, over the past century, evolved into organ, cellular, subcellular, and instrumental subspecies that occupy their special, perhaps unique, niche of medical activity. The quest for a safe medical niche is understandable but risky. Changes in funding, advances in technology, and new knowledge are transforming the specialist realm. The habitat of medicine may become so over crowded with special species of practitioners that, as with habitat change in nature, extinctions occur. Perhaps if the medical tree breaks off a branch of highly specialized technicians, no longer willing or capable of functioning in the wider role of physicians, they will become identified, in the theme of Sir Squire Spriggs, not as physicians but as technical experts, "to be classed with other practical workers who have equal claim

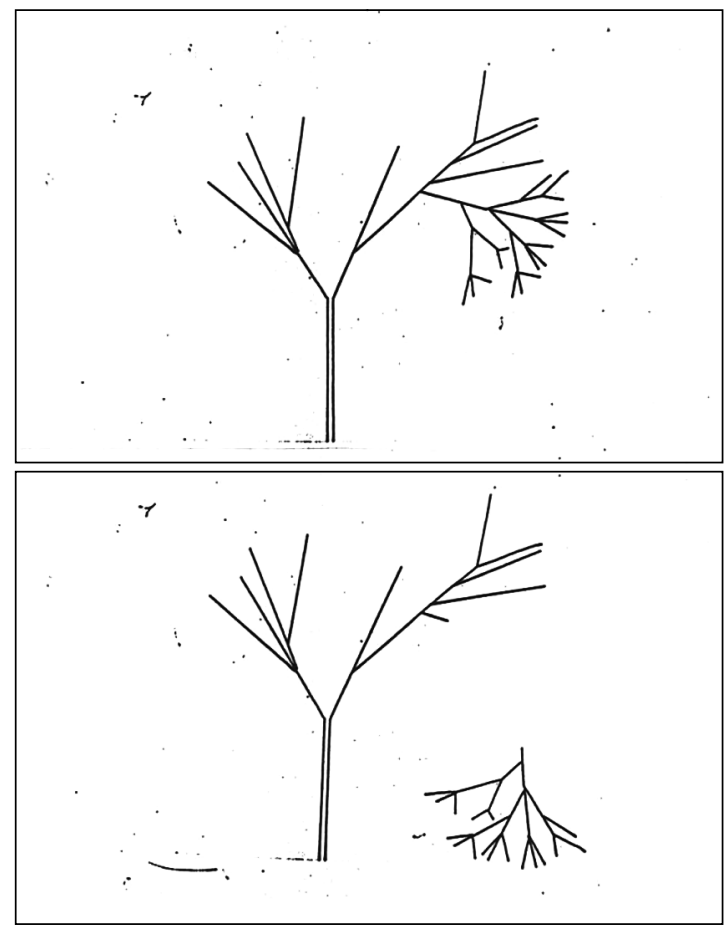

Figure. The broken branch (adapted from Reference 17). 
to be considered men of science". In medicine this perhaps would be a "paradigm change" in the manner of Thomas Kuhn.

I am inclined to think that medicine is an ecosystem with a variety of practitioners that can be taxonomically categorized. I see the biomedical ecosystem becoming similarly crowded with niches filled with technologic specialists that are at risk for extinction as biotechnologic progression grinds ahead, generating new modifications, new tool designs, and ecosystem "climate change". The pluripotent generalist has been eclipsed and obscured by this plethora of highly visible, highly evolved specialists. The generalist, the undifferentiated physician, is the stem cell of the medical ecosystem. I fear that the generalist species, diminished in quantity, resources, and interest, may soon become unable to preserve the physician species and restock the medical ecosystem.

I am terrified by the quest for replacing the personal general physician with impersonal computer, specialized, and specialty internet consultation. To be sure I have a computer, in fact four devices: a laptop, an iPad, a desktop, and a Blackberry. I teach female, male, and gay medical students, undergraduate and graduate students from diverse ethnic and national origins. I practice in a mightily specialized and super-specialized academic and clinical setting. I lament wrestling with the costconscious, over-regulated insurance bureaucracies, practice plans, and hospital committees. I am looking forward to retirement, but not a retreat from the profession and life I passionately care about. Locally I am known for my oft times comic opposition to the intrusion of computers and wireless devices in the personal interactions among patients and physicians. We might be well served by attention from writers of dystopian fiction to look at our future.

The scenario of a patient seeking advice and treatment exclusively by computer and internet allows the illusion that illness and care can be virtually anonymous. The notion that sickness is anonymous is as offensive to me as is the idea that caring can be impersonal, at a distance, without human presence and touch. Critics of the internet and wireless telephony have pointed out the alterations in human attributes: the depersonalization that intense distance connectivity has generated. They are attributes that perhaps spell the fatal demise of the "doctor-patient relationship".
Computers, personal devices, and the internet have already started to produce ethical and legal problems with indiscrete disclosures and intentional intrusions into personal history and internet based information. Internet doctors can be plagued by importunate patients and imposters. The social networks have opened an entrance for malicious gossip and criminal intrusion with data mining and data gathering. The capacity to subvert and to pervert the internet and computer-based medical records and the electronic conversations between patients and doctors are as powerful and as ubiquitous as the internet.

I am frequently chided for my computer skepticism with assertions that the computer is so convenient and fast. Perhaps -I reply- ... except when the power shuts down and the batteries are empty. The essence of industrial advances with the assembly line, the efficient construction of product, is not the model I welcome for the practice of medicine. Illness has never been efficient or convenient and the philosophy of medicine should not be to care conveniently. Health is a continuous state of inconvenience in defiance of the laws of thermodynamics. General doctors like me are labeled as inconvenient, obstructions to the advance of medicine and medical care. Nor is our obstruction really only simple skepticism about the advance of computer and internet in the medical transaction. Electronic medical records are indeed a substantial advance, but with risks in security, longevity, and the variances in electricity supply. A patient, moreover, is more than a medical record. A patient is a live human being whose life, body, and voice are being replaced, submerged by the technologies of imaging, biochemical testing and imaging, and computerization using the ethereal internet in place of in-person conversation and hands-on examination. The virtual patient is in danger of being cared for by the virtual physician.

In 2012 it seems to me that high technology medicine with evolutionary extravagance, dividing medicine into smaller and smaller enclosures, and increasingly dependent upon electrical energy fueled by diminishing resources of carbon based fuel, and fed by transmission cables of increasing length may be an extraordinary gamble. Like all gambles, the risk for failure and bankruptcy is high! Attempting to change the direction and flow of medicine's evolution may be the wrong approach. When the branch breaks, then the 
return of the generalist will be necessary and urgent! Internal medicine's fundamental obligation is to preserve the spirit and practice of general medicine among an outstanding international group in order for that select core to step up and revitalize medicine as a learned profession when the specialized branch falls and fails.

This is a battle about honor and beauty and value in contemporary medicine which has mythic similarity to the stories of the Trojan War of the ancient Greeks. Physicians will have to distinguish between the specialist heroes Achilles and Hector imposing their will upon the world and Odysseus, the crafty many sided sojourner and survivor. Specialists, like the Hector and Achilles of contemporary medicine, will someday have to acknowledge that they are strangers in the medically strange land that they have created. Generalists like Odysseus, able to navigate the real world of human health and illth, will be required to orient the heroes to this real world. Remember, Achilles and Hector are engaged in combat. Each suffers a battlefield death. The real victor is Odysseus, the generalist.

\section{References}

1. Barondess JA. The future of generalism. Ann Intern Med 1993; 119: 153-60.

2. Federated Council for Internal Medicine. General internal medicine and general internists: reorganizing a national need. Ann Intern Med 1992; 117: 778-9.

3. Fitzgerald FT. The case for internal medicine. N Engl J Med 1993; 328: 654-6.
4. Ginzberg E. Physician supply policies and health reform. JAMA 1992; 268: 3115-8.

5. Inui TS, Nolan JP, eds. Internal medicine: curriculum reform. Ann Intern Med 1992; 1165 (suppl): 1041-115.

6. Kassirer JP. Primary care and the affliction of internal medicine. N Engl J Med 1993; 328: 648-50.

7. Lansky NG. Recruiting for primary care. N Engl J Med 1993; 328: 656-60.

8. Petersdorf RG. Financing medical education--a university "Berry plan" for medical students. N Engl J Med 1993; 328: 651-4.

9. Rivo ML. Internal medicine and the journey to medical generalism. Ann Intern Med 1993; 119: 146-52.

10. Rosenblatt RA. Specialists or generalists: on whom should we base the American health care system? JAMA 1992; 267: 1665-6.

11. Schroeder SA. The troubled profession: is medicine's glass half full or half empty? Ann Intern Med 1992; 116: 583-92.

12. Benjamin WW. Healing by the fundamentals. N Engl J Med 1984; 311: 595-7.

13. Lee RV. The jaundiced eye: generalism in general. Amer J Med 1995; 98: 304-6.

14. Perlman RL. Evolutionary biology: a basic science for medicine in the $21^{\text {st }}$ century. Perspectives Biol Med 2011; 54: 75-88.

15. Pietsch TW. Trees of Life: a Visual History of Evolution. Baltimore, Johns Hopkins University Press, 2012, pp. $1-6$.

16. Eldredge N. Darwin: Discovering the Tree of Life. WW Norton, New York, 2005, pp. 1-240.

17. Darwin C. On the Origin of Species by Means of Natural Selection. London, John Murray, Albemarle Street, 1859. (diagram following p. 117). 